\title{
Injection molding of bushes made of tribological PEEK composites
}

\author{
F. Quadrini*, E. A. Squeo \\ Department of Mechanical Engineering, University of Rome Tor Vergata Via del Politecnico n¹, 00133 Rome, Italy
}

Received 27 July 2007; accepted in revised form 24 October 2007

\begin{abstract}
Polyetheretherketone (PEEK) composites have been extensively studied because of the excellent tribological behavior among plastics. However, laboratory specimens and tests are generally discussed, whereas application studies on industrial components are infrequent. In this paper, an injection molded bush made of tribological PEEK was analyzed to correlate wear behavior and molded material structure. Bushes were tested under unlubricated sliding conditions by means of a short wear test. Surface analysis, differential scanning calorimetry (DSC) and optical microscopy were used to evaluate the distribution of the different composite fillers (polytetrafluoroethylene, PTFE, graphite particles and carbon microfibers) and their effect on the final bush behavior. A significant lack of homogeneity was observed in the molded bush and black bands appeared on the shaft surface after testing due to the sliding. The bush geometry and the injection molding process should be optimized to allow the best tribological behavior of the molded material under working conditions.
\end{abstract}

Keywords: polymer composites, injection molding, PEEK, bushes

\section{Introduction}

High performance polymers are used for a lot of industrial applications because of their excellent mechanical properties that are preserved also at high temperatures. Polyetheretherketone is probably the most attractive among high performance polymers, even if its use is limited by the high cost of supplying and processing and by the high sensibility to the molding processes. PEEK is generally used as matrix for high performance composites. Tribological components (such as bushes and gears) can be fabricated by injection molding of a PEEK matrix composite, filled with polytetrafluoroethylene (PTFE), graphite particles and carbon micro-fibers. The maximum amount of filler is generally limited to $30 \mathrm{wt} \%$ to avoid problems during injection; PTFE and graphite enhance the tribological behavior of the molded part, whereas the carbon

*Corresponding author, e-mail: quadrini@ing.uniroma2.it (C) BME-PT and GTE fibers are responsible for the high mechanical performances.

Injection molding is not the only method for making slide-bearing bushes of PEEK composites. In many industrial applications, machining is preferred because of the maintenance and the smallmedium scale production series. Injection molded parts are often not allowed to operate due to uneven stress distribution, whereas machined parts tribologically perform better. However, for large scale production series, the injection molding is the only possible choice for bush making and problems related to the lower performances could limit significantly the use of these materials.

In the scientific literature there are a lot of works about the tribology of PEEK, its blends and its composites because of the high industrial interest in these materials. These materials are generally tested under dry sliding conditions [1-4]. Solid particle erosion behavior during sliding [5] and the 
correlation between mechanical properties and tribology performance $[6,7]$ were also deeply discussed. Due to the complexity of the problem, statistical techniques [8] and neural networks [9] were used to study the effect of test parameters on the dry sliding tribological behavior. Moreover, thermal aging can significantly affect the tribological performance of PEEK and short fiber reinforced PEEK composites [10].

The investigation on the tribology performance of PEEK, PEEK blends and composites was also extended to water lubricated sliding contacts [11-15], different wear modes [16] and harsh operating conditions [17]. In order to obtain the best tribological behavior, the effect of nano-fillers was discussed (SiC [18, 19], alumina [20-21] and PTFE [20] nano-particles, carbon nanofibers [22], nanotubes and nano-onions [20]).

The mentioned papers show that PEEK composites have excellent tribological performance among plastics, but the correlation between the injection molding technology and the tribological performance of the molded part has never been investigated. Small laboratory specimens are generally preferred. In 2002, Zsidai et al. deeply discussed advantages and disadvantages of small-scale tribotesting [23]. In 2005, Samyn and De Baets studied the friction and wear of acetal, focusing on the effect of the specimen scale on the final measured properties [24]. They assessed that to obtain relevant data for practical design of polymer sliding parts, it is necessary to simulate real working conditions as close as possible on laboratory scale. However, they did not discuss that, besides the specimen scale, also the molding process can affect the result of friction and wear tests. In order to avoid scale problems, a purely experimental approach is often used. Plastic gears made of carbon fiber reinforced PEEK [25-26] or acetal [27-28] were directly tested in working-like conditions. A similar study was never performed on slide-bearing bushes.

In the current work, the authors investigate the capability of a bush made of PEEK composite to substitute a traditional bush made of brass. All the mentioned scientific papers show the high tribological properties of this material, but they do not discuss application cases. Therefore, it is not obvious that injection molded bush behavior under working conditions could be satisfactory.

\section{Materials and methods}

Commercial bushes were acquired by a manufacturer who started to produce the component depicted in Figure 1 in several high performance polymers. This bush was designed for small size electric motors instead of a traditional brass because of the low weight and production time. The two cavity mold was adapted to injection mold the bush in PEEK 450 FC 30 (by Victrex, USA) which is a $10 \mathrm{wt} \%$ carbon fiber, $10 \mathrm{wt} \%$ graphite, $10 \mathrm{wt} \%$ PTFE filled PEEK. PEEK 450 FC 30 is a commercial material developed for injection molding and investigated in some scientific studies [4-6, 14]. At room temperature, it has a tensile modulus of 10.1 GPa, a tensile strength of $134 \mathrm{MPa}$, a thermal conductivity of $0.78 \mathrm{~W} \cdot \mathrm{m}^{-1 .}{ }^{\circ} \mathrm{C}^{-1}$ and a specific heat capacity of $1.8 \mathrm{~kJ} \cdot \mathrm{kg}^{-1} \cdot{ }^{\circ} \mathrm{C}^{-1}$. The manufacturer assured that the molding conditions suggested by the material supplier were observed (mainly the melt temperature of $380^{\circ} \mathrm{C}$ and the mold temperature of $180^{\circ} \mathrm{C}$ ).

The bushes were used for a short wear test and for material analyses. The wear test was carried out keeping the bush in a standstill position and matching a stainless steel shaft (Figure 2). The shaft was fixed coaxially to the rotor of an electric motor and was put into rotation at $3000 \mathrm{rpm}$ for $10 \mathrm{~min}$. As the shaft diameter was $6 \mathrm{~mm}$, the resulting sliding speed was $0.942 \mathrm{~m} / \mathrm{s}$. The bush was mounted on the shaft without interference, therefore a minimum load was present on it in dependence of the weight of the electric motor that was shared by the supports. As an approximation, the load on the bush was about $10 \mathrm{~N}$ and the consequent $p v$ (pressurespeed) value was $0.10 \mathrm{MPa} \cdot \mathrm{m} / \mathrm{s}$.

During the test, the bush temperature was acquired by means of a BS1843 standard type $K$ thermocou-

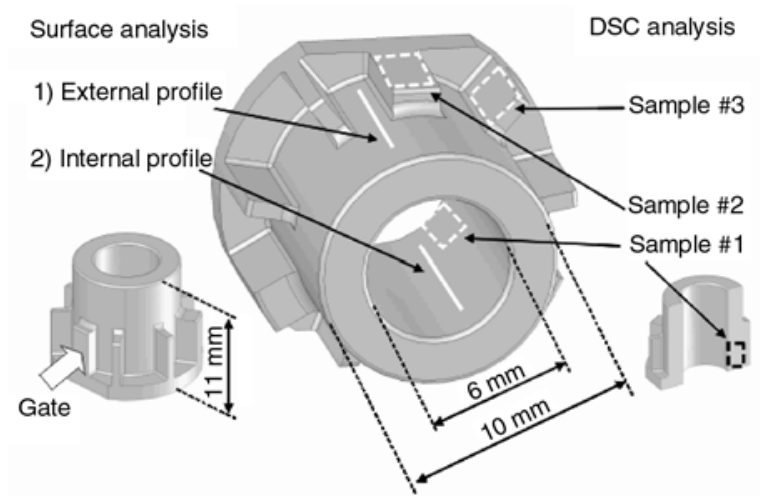

Figure 1. Molded bush dimensions and position of surface and DSC analyses 


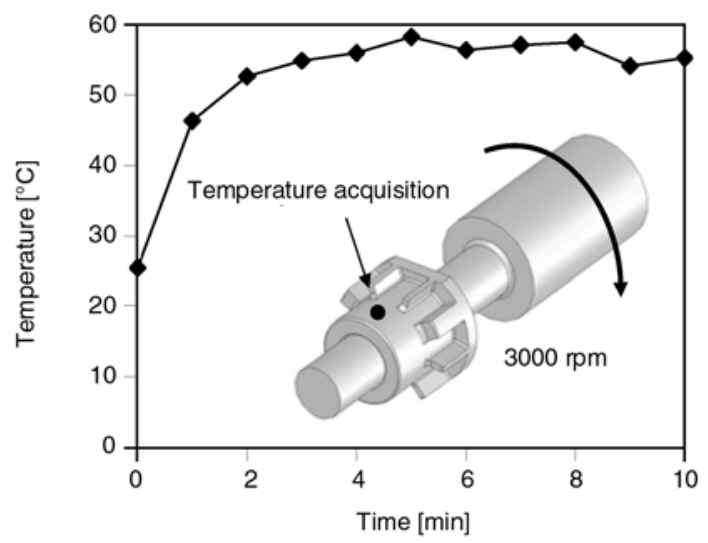

Figure 2. Configuration of the short wear test and temperature acquisition during the test

ple placed on the external surface. A typical temperature curve is reported in Figure 2; after 5 min a plateau is already reached about $55^{\circ} \mathrm{C}$, which is relatively low for this material (the continuous mechanical use temperature without impact is $240^{\circ} \mathrm{C}$ ). Ten bush-shaft couples were used in the short wear test. A surface analysis was performed on a bush by means of a scanning surface topography instrument (by Taylor Hobson, Talysurf CLI 2000). As Figure 1 shows, two external lines were chosen for the profile acquisition, the first along the height of the internal cylindrical surface and the second along the height of the external surface. The internal profile was acquired both before and after the short wear test. Also the shaft profile was acquired along the height of the bearing zone.

Some samples were extracted from a bush to carry out DSC tests (by Netzsch DSC 200 PC). In Figure 1 the position of the samples is shown. DSC tests were carried out from room temperature to $400^{\circ} \mathrm{C}$ at $10^{\circ} \mathrm{C} / \mathrm{min}$. Other bushes were cut and prepared for optical microscopy.

\section{Experimental results}

Several bush-shaft couples were used in the short wear test and always the same result was obtained for the shaft: some black bands appeared on the shaft after a few seconds during the test. These bands were not removable by conventional clean-

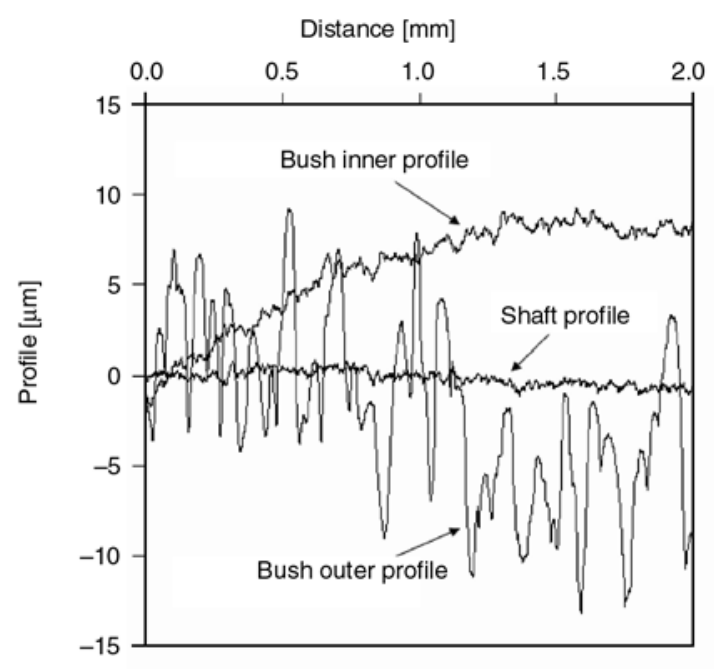

Figure 3. Acquired profiles of the molded bush and the steel shaft before the short wear test

ing techniques (such as ultrasounds) but only by machining. The same bushes were used for the microscopical analyses.

The roughness profiles of a bush and a shaft, acquired before the short wear test, are reported in Figure 3. In this figure, the raw data are shown without any filtering and the sample positioning is responsible for the trend. In Table 1 the roughness data extracted from the profiles are collected before and after the test. In Figure 4 the DSC scans performed on 3 samples extracted from the bush are shown. In Figure 5 one of these scans (sample \#1 of Figure 1) was compared with two scans performed

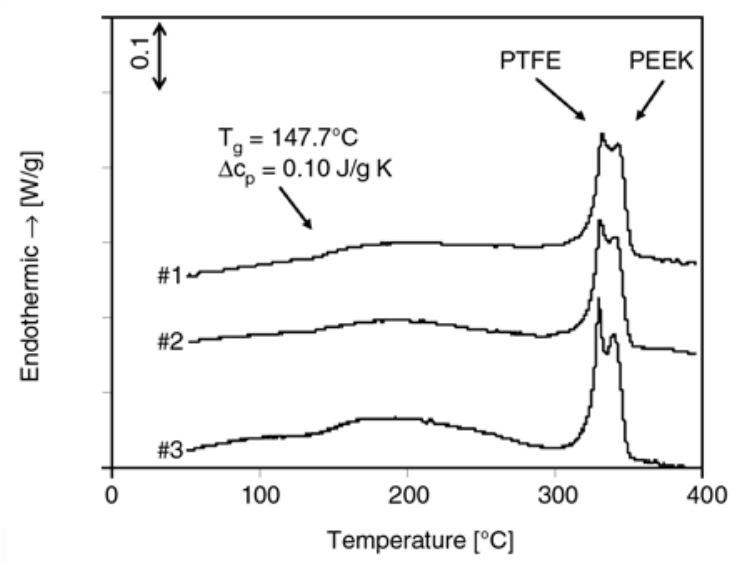

Figure 4. DSC scans performed on samples extracted in different points of the bush

Table 1. Results from surface analysis of the bush, before and after the short wear test

\begin{tabular}{|l|c|c|c|c|c|}
\hline \multirow{2}{*}{} & \multicolumn{3}{|c|}{ Bush profile } & \multicolumn{2}{c|}{ Shaft } \\
\cline { 2 - 4 } & \multirow{2}{*}{ External } & \multicolumn{2}{|c|}{ Internal } & \multirow{2}{*}{ (Before test) } & \\
\cline { 2 - 5 } & & (Before test) & (After test) & 0.174 & 0.15 \\
\hline$R_{a}[\mu \mathrm{m}]$ & 2.53 & 0.597 & 0.627 & 2.02 & 1.42 \\
\hline$R_{t}[\mu \mathrm{m}]$ & 18 & 9.73 & 10.4 & \\
\hline
\end{tabular}




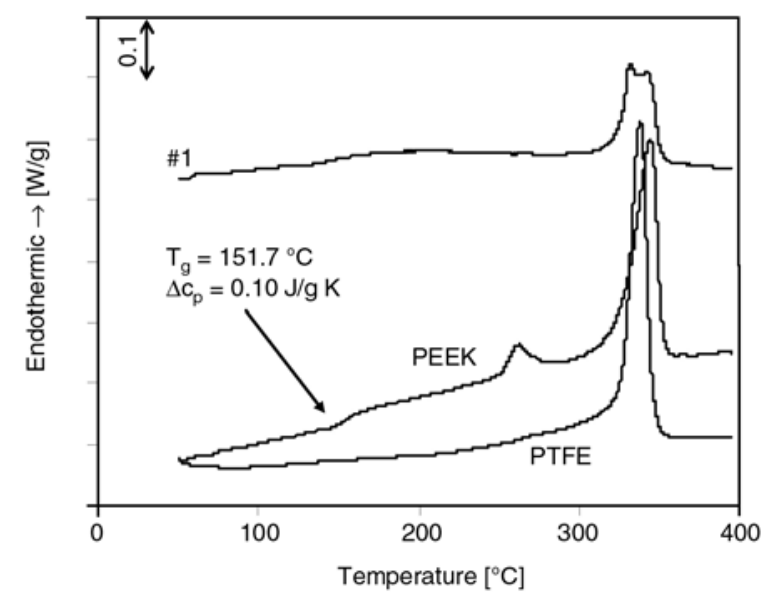

Figure 5. Comparison between a DSC scan of a sample extracted from the bush and the scans of PEEK and PTFE bulk samples

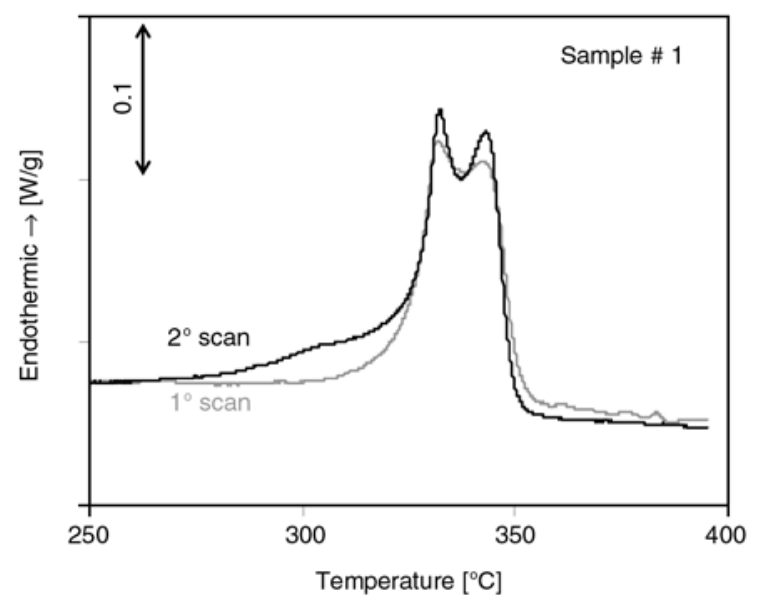

Figure 6. Comparison between the first and second DSC scans carried out on the same sample

on bulk PTFE and PEEK that were extracted from commercial bars. In Figure 6 another comparison is shown between two successive DSC scans of the same sample \#1. From all the curves of Figures 4-6 both the area of the peak and the temperature of the peak were extracted and reported in Figure 7. The area was calculated after the baseline correction and corresponds to the material melting heat, whereas the temperature is the melting temperature. A double melting peak was observed for all the samples extracted from the bush, therefore two different temperatures are reported for each sample. Figures 8, 9 and 10 show respectively the structure of the molded material in the bulk, the bearing zone and the external surface; in Figure 9 the aspect of the shaft is also superimposed. In conclusion, Figure 11 shows a magnification of the composite structure near the external surface (a) and the bearing zone (b-c).
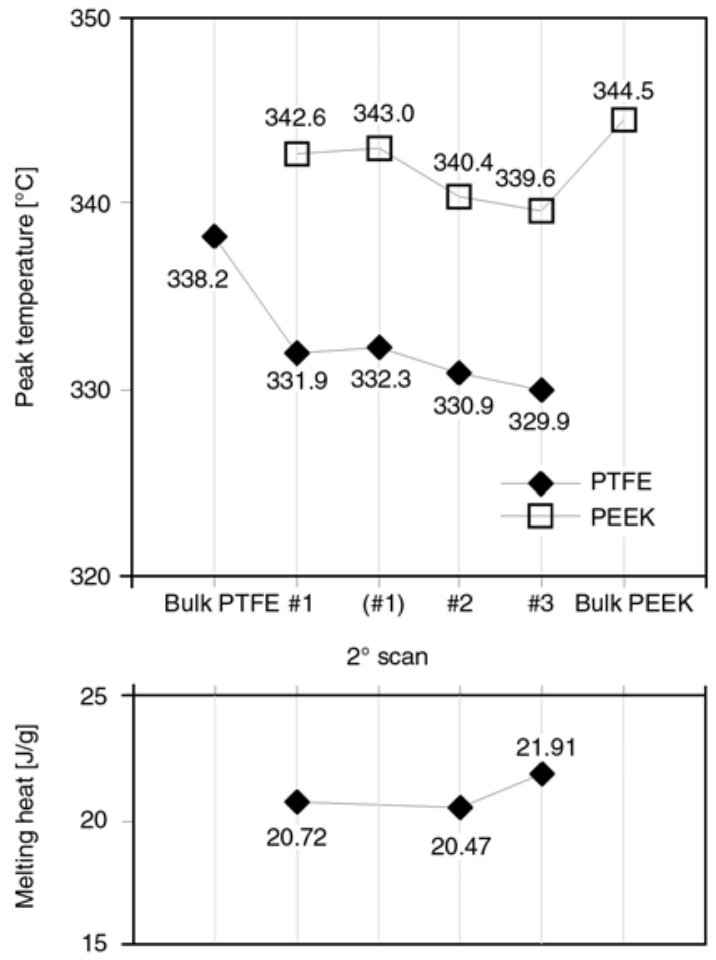

Figure 7. Temperature of the peak and melting heat extracted from the DSC scans

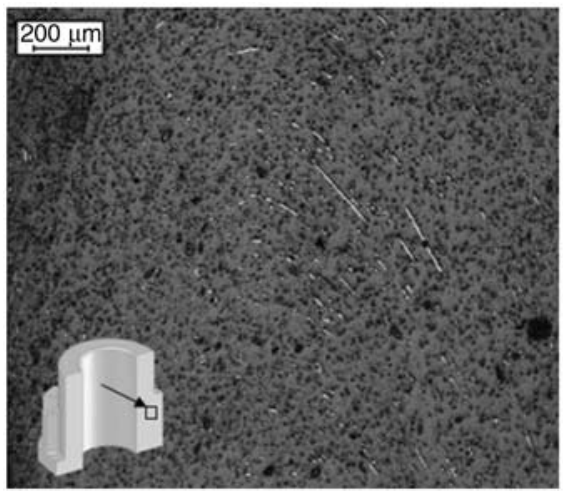

Figure 8. Optical micrograph of the bulk molded material

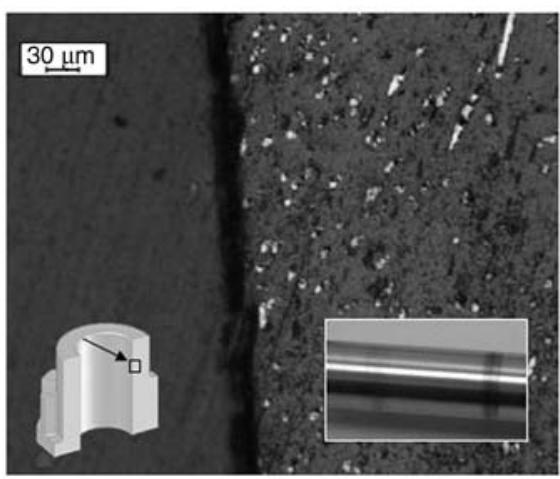

Figure 9. Optical micrograph in the bush bearing zone and aspect of the shaft after the wear test 


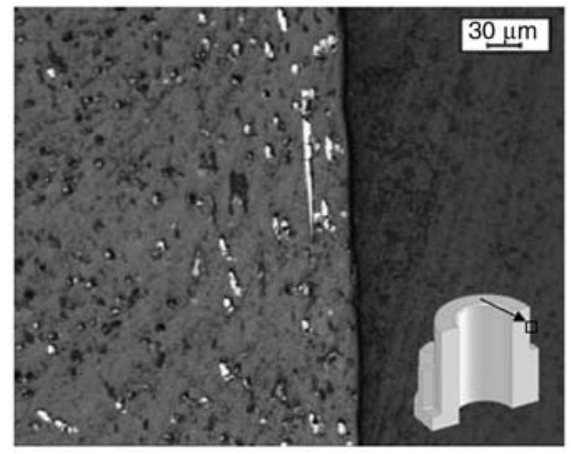

Figure 10. Optical micrograph near the bush external surface

\section{Discussion}

During the wear test, the temperature increases up to $55^{\circ} \mathrm{C}$ in the first $4 \mathrm{~min}$ and then it is almost constant. The temperature is low enough to exclude any possible degradation of the material. Nevertheless a strong interaction occurs between the shaft and the bush due to deposition of PEEK composite debris on the shaft surface.

As expected, the acquired profiles of the bush and the shaft are very different from one another (Figure 3). The shaft profile is the smoothest; the bush internal profile is rougher but enormously smoother than the external profile. Comparing data before and after the test (Table 1), the shaft roughness (in terms of $R_{a}$ and $R_{t}$ ) decreases because of the test, whereas the bush inner profile becomes rougher. A small amount of material is transferred from the bush to the shaft; the bush is minimally damaged, therefore its roughness increases; the valleys of the shaft profile are filled with the plastic material and so the shaft roughness decreases. This is a typical phenomenon that can be observed during the sliding of steel on a polymeric surface under unlubricated running conditions. A similar phenomenon was already discussed by Jacobs et al. for the same PEEK composite [14]. A transfer film containing carbon fiber debris can form on the steel counterpart and modify the wear curve. They also discussed that in aqueous environment the formation of the transfer film seems to be disturbed by tribocorrosion. However, the testing conditions were very different in terms of wear test (a ball on-prism tribometer) and sliding speed $(28.2 \mathrm{~mm} / \mathrm{s})$, even if the $p v$ term is almost comparable.

DSC analysis allows studying the effect of the injection molding process on the molded material. All the samples present the inflection point related to the PEEK glass transition (at about $150^{\circ} \mathrm{C}$ ) and a double melting peak (Figure 4). The shape of a DSC scan depends, among other things, on the core-skin effect; however the double peak is related to the presence, inside the PEEK matrix, of PTFE which melts at a lower temperature. In fact, in Figure 5 the scan of sample \#1 is plotted together with the scan of samples of pure PEEK and pure PTFE. The superposition of the bulk PEEK and PTFE peaks is very similar to the shape of the melting peak of sample \#1. Figure 6 shows the comparison between the first and second DSC scans performed on the sample \#1. In both scans, two peaks are visible and the difference is negligible. As the first sample melting does not eliminate the presence and the position of the two peaks, these have to be related to the material composition and not to the core-skin effect.

Observing Figure 4, the extent of the PTFE peak is dependent on the amount of PTFE in the sample. PTFE content differs from point to point. This occurrence was never discussed before. The lowest PTFE peak is visible in sample \#1, i. e. in the bearing zone. The peak increases in the large rib (sam-
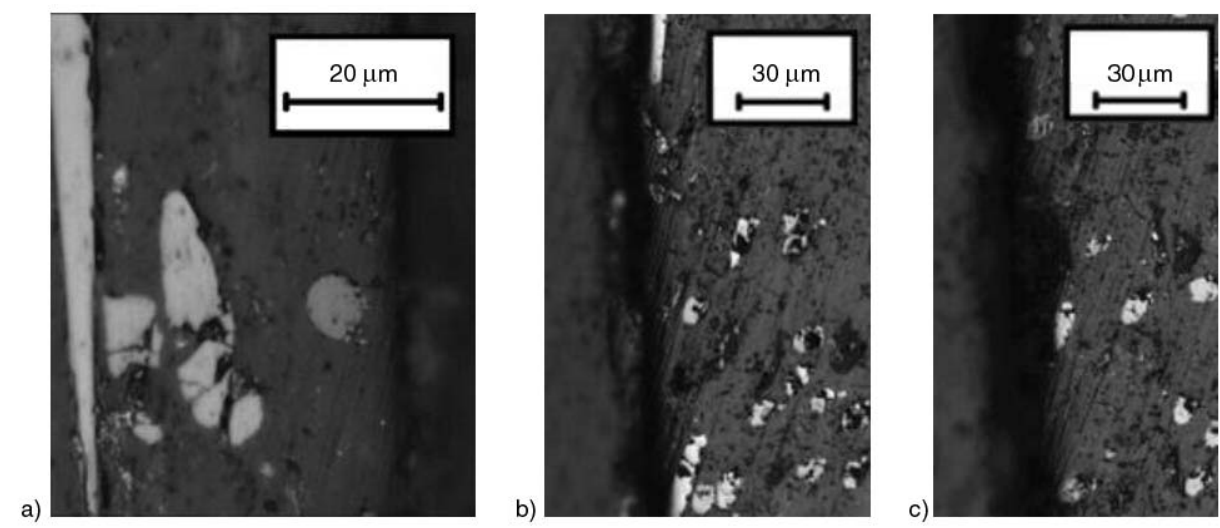

Figure 11. Magnification of the micrographs of the bushes after testing: near the external surface (a) and the bearing zone (b-c) 
ple \#2) and has a maximum in the small rib (sample \#3). Actually, the ribs were inserted in the bush geometry only to reproduce the shape of a typical bush made of metal. In fact, many industrial applications deal with the substitution of metallic parts with plastic parts having the same shape, above all for commercial reasons, but also to allow the substitution without any modification in the assembly procedure. A lack of homogeneity in the PTFE distribution can occur because of the complex shape of the bush and other factors, such as the ratio between the viscosities of PEEK and PTFE. Moreover, considering the gate position (Figure 1), during molding carbon fibers are pushed against the bearing zone, rather than toward the ribs. Carbon fibers are present in tribological PEEK mainly to enhance the structural properties; their agglomeration in the bearing zone could be dangerous, PTFE or graphite would be better. DSC data of Figure 7 confirm this statement, as the highest melting heat is measured for sample \#3. In fact, melting heat is related to PTFE and PEEK content in the sample, as only these two materials can melt. From Figure 7 , it is also clear that the temperatures of the peak are almost constant along the bush, for both materials. Nevertheless, the highest values are observed for the bulk materials, because of the different nature of the polymers.

The injection stage affects the homogeneity of the molded tribological PEEK, as the PTFE, that should help the sliding, is far form the sliding zone, whereas the carbon fibers, that should guarantee the bulk strength, are close to the bearing zone. In order to deepen this aspect, optical microscopy was used to investigate the structure of the molded bushes. In Figure 8 the micrograph of the bulk material is shown: the heterogeneous nature of the PEEK composite is clear. As discussed in [6], the black dots correspond to PTFE; the small shining particles to graphite; the shining filaments to carbon fibers. Due to the injection phase, the carbon fiber orientation is complex. Dealing with PEEK 450 FC 30, previous papers have never investigated the effect of the fiber orientation on transfer film formation and tribological behavior. It is well-known that fibers strongly contribute to the definition of the tribology system but it is hard to understand which is the best orientation distribution. For this reason, testing the real bush in working-like conditions seems to be the only way to investigate its suitability for industrial applications.
In Figure 9 the structure of the composite material near the bearing zone is shown, together with the aspect of the steel shaft after test. After the test, some black parallel bands appear on the shaft due to the transfer film. In Figure 10 the same structure is observed near the external surface. Figures 9 and 10 seem similar, but this similarity disappears after magnification. In the external wall, all the carbon fibers are covered by a thin film of plastic (Figure 11a). In the bearing zone, after a few seconds under working conditions, the same plastic film is removed from the surface by the shaft sliding and the carbon fibers rise (Figures 11b and c). Observing the rising carbon fibers at the internal wall, it is clear that they were leveled by sliding. The transfer film formation damages the bush roughness and alter the aspect of the shaft.

\section{Conclusions}

In the scientific literature, industrial bushes were never investigated; in this paper, a short wear test was performed on a bush made of composite PEEK. The material showed the expected high properties by limiting the maximum bush temperature reached during the test. The transfer film formation was observed, as well as an increase in the bush roughness. Even if the transfer film could improve the tribological behavior of the bush-shaft system, the presence of debris and the increase of the bush roughness could be negative factors. Moreover, in working conditions, tribo-corrosion could occur in aqueous environment, in dependence of the shaft alloy. These phenomena should be taken into account to evaluate the suitability of the PEEK composite bush for industrial applications. For many industrial applications, it is mandatory that no traces can be left by the bush on the shaft surface. In this case, this kind of material should be avoided. However, even if the deposition of a transfer film is accepted, the molding process of the bush in tribological PEEK should be optimized to maximize the expected performance of the composite; on the contrary, in the industrial practice, the molding process is designed only to obtain the desired geometrical tolerances of the molded part. The heterogeneous nature of the composite material could damage the tribological behavior of the bush; after molding, the PTFE and graphite particles (useful to reduce friction) should be agglomerated near the bearing zone; instead the carbon fibers 
should be far enough from there. Injection stage and bush geometry have to be designed carefully. The bush geometry used in this study does not seem to be recommendable for industrial application.

\section{References}

[1] Eiss N. S. J., Hanchi J.: Tribological behavior of polyetheretherketone, a thermotropic liquid crystalline polymer and in situ composites based on their blends under dry sliding conditions at elevated temperatures. Wear, 200, 105-121 (1996).

[2] Stuart B. H.: Tribological studies of poly(ether ether ketone) blends. Tribology International, 31, 647-651 (1998).

[3] Zhang M. Q., Zai P. L., Friedrich K.: Thermal analysis of the wear debris of polyetheretherketone. Tribology International, 30, 103-111 (1997).

[4] Harsha A. P., Tewari U. S.: Tribo performance of polyaryletherketone composites. Polymer Testing, 21, 697-709 (2002).

[5] Harsha A. P., Tewari U. S., Venkatraman B.: Solid particle erosion behaviour of various polyaryletherketone composites. Wear, 254, 693-712 (2003).

[6] Zhang Z., Breidt C., Chang L., Friedrich K.: Wear of PEEK composites related to their mechanical performances. Tribology International, 37, 271-277 (2004).

[7] Long C-G., Wang X-Y.: Mechanical properties and tribology performance of the Ekonol-PEEK composite. Journal of Reinforced Plastics and Composites, 23, 1575-1582 (2004).

[8] Davim J. P., Cardoso R.: Tribological behaviour of the composite PEEK-CF30 at dry sliding against steel using statistical techniques. Materials and Design, 27, 338-342 (2006).

[9] LiuJie X., Davim J. P., Cardoso R.: Prediction on tribological behaviour of composite PEEK-CF30 using artificial neural networks. Journal of Materials Processing Technology, 189, 374-378 (2007).

[10] Sinmazçelik T., Yilmaz T.: Thermal aging effects on mechanical and tribological performance of PEEK and short fiber reinforced PEEK composites. Materials and Design, 28, 641-648 (2007).

[11] Yamamoto Y., Takashima T.: Friction and wear of water lubricated PEEK and PPS sliding contacts. Wear, 253, 820-826 (2002).

[12] Yamamoto Y., Hashimoto M.: Friction and wear of water lubricated PEEK and PPS sliding contacts. Part 2. Composites with carbon or glass fibre. Wear, 257, 181-189 (2004).

[13] Jia J., Chen J., Zhiu H., Hu L.: Comparative study on tribological behaviors of polyetheretherketone composite reinforced with carbon fiber and polytetrafluoroethylene under water-lubricated and dry-sliding against stainless steel. Tribology Letters, 17, 231-238 (2004).
[14] Jacobs O., Jaskulka R., Yan C., Wu W.: On the effect of counterface material and aqueous environment on the sliding wear of various PEEK compounds. Tribology Letters, 18, 359-372 (2005).

[15] Unal H., Mimaroglu A.: Friction and wear characteristics of PEEK and its composite under water lubrication. Journal of Reinforced Plastics and Composites, 25, 1659-1667 (2006).

[16] Bijwe J., Sen S., Ghosh A.: Influence of PTFE content in PEEK-PTFE blends on mechanical properties and tribo-performance in various wear modes. Wear, 258, 1536-1542 (2005).

[17] Lal B., Alam S., Mathur G. N.: Tribo-investigation on PTFE lubricated PEEK in harsh operating conditions. Tribology Letters, 25, 71-77 (2006).

[18] Wang Q-H., Xu J., Shen W., Xue Q.: The effect of nanometer $\mathrm{SiC}$ filler on the tribological behavior of PEEK. Wear, 209, 316-321 (1997).

[19] Wang Q-H., Xue Q-J., Liu W-M., Chen J-M.: Effect of nanometer $\mathrm{SiC}$ filler on the tribological behavior of PEEK under distilled water lubrication. Journal of Applied Polymer Science, 78, 609-614 (2000).

[20] McCook N. L., Hamilton M. A., Burris D. L., Sawyer W. G.: Tribological results of PEEK nanocomposites in dry sliding against $440 \mathrm{C}$ in various gas environments. Wear, 262, 1511-1515 (2007).

[21] Qiao H-B., Guo Q., Tian A-G., Pan G-L., Xu L-B.: A study on friction and wear characteristics of nanometer $\mathrm{Al}_{2} \mathrm{O}_{3} / \mathrm{PEEK}$ composites under the dry sliding condition. Tribology International, 40, 105-110 (2007).

[22] Werner P., Alstädt V., Jaskulka R., Jacobs O., Sandler J. K. W., Shaffer M. S. P., Windle A. H.: Tribological behaviour of carbon-nanofibre-reinforced poly(ether ether ketone). Wear, 257, 1006-1014 (2004).

[23] Zsidai L., De Baets P., Samyn P., Kalácska G., Van Peterghen A. P., Van Parys F.: The tribological behavior of engineering plastics during sliding friction investigated with small-scale specimens. Wear, 253 , 673-688 (2002).

[24] Samyn P., De Baets P.: Friction and wear of acetal: A matter of scale. Wear, 259, 697-702 (2005).

[25] Kurokawa M., Uchiyama Y., Nagai S.: Performance of plastic gear made of carbon fiber reinforced polyether-ether-ketone. Tribology International, 32, 491497 (1999).

[26] Kurokawa M., Uchiyama Y., Nagai S.: Performance of plastic gear made of carbon fiber reinforced polyether-ether-ketone: Part 2. Tribology International, 33, 715-721 (2000).

[27] Kim C. H.: Durability improvement method for plastic spur gears. Tribology International, 39, 1454-1461 (2006).

[28] Mao K., Hooke C. J., Walton D.: Acetal gear wear and performance prediction under unlubricated running condition. Journal of Synthetic Lubrication, 23, 137152 (2006). 